\title{
Measuring the Rates of Transcriptional Elongation in the Female Drosophila melanogaster Germ Line by Nuclear Run-on
}

\author{
A. Sigova, V. VAgin, AND P.D. Zamore \\ Department of Biochemistry and Molecular Pharmacology, University of Massachusetts Medical School, \\ Worcester, Massachusetts 01605
}

\begin{abstract}
We adapted the nuclear run-on method to measure changes in the rate of RNA polymerase II (pol II) transcription of repetitive elements and transposons in the female germ line of Drosophila melanogaster. Our data indicate that as little as an approximately 1.5 -fold change in the rate of transcription can be detected by this method. Our nuclear run-on protocol likely measures changes in transcriptional elongation, because rates of transcription decline with time, consistent with a low rate of pol II re-initiation in the isolated nuclei. Surprisingly, we find that the retrotransposon gypsy and the repetitive sequence mst40 are silenced posttranscriptionally in fly ovaries.
\end{abstract}

Eukaryotic genomes exist as chromatin (from the Greek chroma, meaning colored), a complex of DNA and histone proteins that facilitates efficient DNA packaging and differential regulation of gene expression. Cytologically, chromatin can be divided into heterochromatin, first identified by its dark staining, and euchromatin, which stains more lightly (Zacharias 1995). Heitz imagined euchromatin to be genetically active and rich in genes (Zacharias 1995). In contrast, he proposed heterochromatin to be genetically inert and gene-poor. Nearly eight decades later, his prescient assessment stands essentially uncorrected.

Constitutive heterochromatin ( $\alpha$-heterochromatin) comprises tandem arrays of repetitive DNA sequences ("satellite" sequences), punctuated occasionally by insertions of transposable elements. Constitutive heterochromatin is believed to organize specialized structures such as centromeres and telomeres that act to maintain genetic stability and ensure the segregation of chromosomes during mitosis and meiosis (Allshire et al. 1995; Nimmo et al. 1998; Bernard et al. 2001; Pidoux and Allshire 2005; Huang and Moazed 2006). Heterochromatic states are epigenetically inherited: The DNA packaging state is maintained after replication and mitosis, irrespective of the underlying DNA sequence (Elgin and Grewal 2003). At the molecular level, all heterochromatic regions contain lysine 9-methylated histone 3 and the evolutionarily conserved heterochromatic protein 1 (HP1; Swi6 in fission yeast) (Huisinga et al. 2006). Heterochromatin has other unusual properties: It replicates late in $\mathrm{S}$ phase, remains condensed throughout the cell cycle, resists recombination, and silences reporter genes inserted within or nearby, a property that underlies position-effect variegation (Henikoff 1992; Mahtani and Willard 1998; Copenhaver et al. 1999; Puechberty et al. 1999; Gilbert 2002; Schubeler et al. 2002). In contrast, facultative heterochromatin is transcriptionally active, but it can adopt the structural and functional characteristics of heterochromatin under special circumstances. Examples of facultative heterochromatin include the inactive $\mathrm{X}$ chromosome of mammals (which is genetically identical to its active sister); the silenced rRNA genes in nucleolar dominance, a phenomenon in which rRNA genes of only one parent are active in animal and plant hybrids; and the developmentally regulated $\beta$-globin locus in animals (Weintraub et al. 1981; Forrester et al. 1989; Lewis and Pikaard 2001; Grummt and Pikaard 2003; Kim and Dean 2004; Lawrence and Pikaard 2004; Lawrence et al. 2004; Heard 2005).

Between constitutive heterochromatin and euchromatin lies $\beta$-heterochromatin, which is less condensed, largely deficient in tandem sequence arrays, filled with copies of numerous transposable element families, and contains few functional genes (Holmquist et al. 1998). Repetitive sequences account for the majority of all heterochromatic sequences in Drosophila melanogaster, whose genome is $30 \%$ heterochromatic, suggesting that they have a central role in heterochromatin assembly. Sequence comparison of the D. melanogaster fourth chromosome, which is largely heterochromatic, with the syntenic Drosophila virilis chromosome 6 , which is euchromatic, suggests that the difference in chromatin packaging reflects the density and distribution of transposable elements (Riddle and Elgin 2006; Slawson et al. 2006).

The predominance of repetitive elements in heterochromatin suggests that these selfish genetic elements are silenced transcriptionally. Repetitive element silencing is essential for genome integrity, as their transposition is the major source of genome rearrangements (Kazazian 2004). In plants, animals, and fungi, RNA silencing has been implicated as a major defense against repetitive element transposition (Martienssen and Colot 2001; Sijen and Plasterk 2003; Kalmykova et al. 2005; Nolan et al. 2005; Savitsky et al. 2006). In the male and female germ line of D. melanogaster, retrotransposons and repetitive sequences are silenced by the repeat-associated small RNA (rasiRNA) pathway (Vagin et al. 2006), an RNA silencing mechanism distinct from both the RNA interference (RNAi) and microRNA (miRNA) pathways. Small silencing RNAs 24-30 nucleotides long, rasiRNAs not only are about $3-7$ nucleotides longer than siRNAs and 
miRNAs, but they are also chemically different, in that they lack one of the 3 '-terminal hydroxyl groups characteristic of animal short interfering RNAs (siRNAs) and miRNAs. Consistent with this chemical difference, rasiRNAs may not be produced by either Dicer-1, which makes Drosophila miRNAs, or Dicer-2, which makes siRNAs. rasiRNA-directed silencing of repetitive genetic elements requires the putative helicases $\mathrm{Spn}-\mathrm{E}$, and Armitage as well as Piwi or Aubergine, members of the Piwi subclade of Argonaute family of proteins.

Supporting the view that rasiRNAs act to silence repetitive sequence by reducing their rate of transcription, mutations in spn-E, aubergine, and piwi are reported to cause loss of lysine-9 methylation of histone $\mathrm{H} 3$ on silenced genes (Pal-Bhadra et al. 2004). Historically, heterochromatin has been regarded as transcriptionally inert, but new evidence in fission yeast suggests that heterochromatin can be transcribed by RNA pol II and then silenced by the posttranscriptional destruction of the nascent transcript, perhaps at its site of transcription (Volpe et al. 2002; Djupedal et al. 2005; Kato et al. 2005; Buhler et al. 2006).

What mechanism silences repetitive elements in the germ line of any organism is unknown. Mutations in armi increase the steady-state concentration of repetitive element mRNA in the fly germ line (Vagin et al. 2006). Here, we examine the transcriptional rates of the silenced and desilenced retrotransposon gypsy and the repetitive sequence male-specific transcript 40 (mst40) in the D. melanogaster female germ line. Contrary to expectation, we find that loss of gypsy or $m s t 40$ silencing caused by loss of the Armi protein is not accompanied by a change in the rate of transcription of either of these selfish genetic elements.

\section{MATERIALS AND METHODS}

Isolation of nuclei. The rate of transcriptional elongation was determined by nuclear run-on analysis essentially as described previously (So and Rosbash 1997). Briefly, ovaries from 50-100 females were dissected with needles into Drosophila Ringer's solution (182 mM KCl, $46 \mathrm{~mm} \mathrm{NaCl}, 3 \mathrm{~mm} \mathrm{CaCl}_{2}, 10 \mathrm{~mm}$ Tris- $\mathrm{HCl}$ at $\mathrm{pH}$ 7.5) and stored on ice in a $1.5-\mathrm{ml}$ homogenization tube (Kontes, Vineland, New Jersey) during isolation. Isolated tissues were centrifuged at $2000 \mathrm{~g}$ at $4^{\circ} \mathrm{C}$, the supernatant discarded, and then homogenized with 20-30 strokes of the pestle in $300 \mu \mathrm{l}$ of homogenization buffer $(10 \mathrm{~mm}$ HEPES-KOH at pH 7.5, $10 \mathrm{mM} \mathrm{KCl,} \mathrm{0.8} \mathrm{M} \mathrm{sucrose,} 1 \mathrm{~mm}$ EDTA, $0.5 \mathrm{~mm}$ dithiothreitol (DTT), and $100 \mu \mathrm{g} / \mathrm{ml}$ yeast tRNA (Ambion, Austin, Texas) containing one tablet of Complete Mini EDTA-free Protease Inhibitor Cocktail (Roche) for each $10 \mathrm{ml}$. An additional $200 \mu \mathrm{l}$ of homogenization buffer was used to rinse the tube. The rinse and the homogenate were pooled and then filtered through a Bio-Spin column (Bio-Rad).

The filtrate was overlaid on a $500-\mu 1$ cushion of $1 \mathrm{M}$ sucrose dissolved in $10 \mathrm{~mm}$ HEPES ( $\mathrm{pH} 7.5$ ), $10 \mathrm{mM} \mathrm{KCl,}$ $10 \%$ glycerol, and $1 \mathrm{~mm}$ EDTA plus one tablet of Complete Mini EDTA-free Protease Inhibitor Cocktail (Roche) for each $10 \mathrm{ml}$ and centrifuged at $10,000 \mathrm{~g}$ for 10 minutes at $4{ }^{\circ} \mathrm{C}$. After discarding the supernatant, the nuclei were resuspended in $500 \mu$ of nuclear resuspension (NR) buffer (40 mM HEPES-KOH at $\mathrm{pH} 8.0,25 \%$ glycerol, $5 \mathrm{~mm}$ magnesium acetate, $1 \mathrm{~mm}$ DTT, and 0.1 $\mathrm{mM}$ EDTA containing for each $10 \mathrm{ml}$ one tablet of Complete Mini EDTA-free Protease Inhibitor Cocktail [Roche]) and centrifuged for 2 minutes at $8000 \mathrm{~g}$ at $4^{\circ} \mathrm{C}$.

Labeling of nascent transcripts. The pellet was resuspended in $195 \mu \mathrm{l}$ of NR buffer, and the reaction was initiated by adding $50 \mu \mathrm{l}$ of $5 \mathrm{x}$ reaction mixture $(5 \mathrm{~mm}$ magnesium acetate; $750 \mathrm{~mm} \mathrm{KCl} ; 2.5 \mathrm{~mm}$ each ATP, CTP, and GTP; 10 mM DTT; $1 \mu$ l of RNasin [Promega]; $50 \mathrm{~mm}$ of creatine phosphate; and $60 \mu \mathrm{g} / \mathrm{ml}$ creatine kinase) and $5 \mu \mathrm{l}$ of $\left[\alpha-{ }^{32} \mathrm{P}\right] \mathrm{UTP}(6000 \mathrm{Ci} / \mathrm{mmol}, 40$ $\mu \mathrm{Ci} / \mu 1$; MP Biomedicals, Irvine, California). After incubation for 30 minutes at $23^{\circ} \mathrm{C}$, the reaction was stopped by adding $25 \mu \mathrm{l}$ of RNase-free DNase (RQ1, Promega) and incubating for 5 minutes at $37^{\circ} \mathrm{C}$. Proteins were digested by adding $20 \mu \mathrm{l}$ of $15 \times$ proteinase buffer $(7.5 \%$ SDS, $150 \mathrm{~mm}$ EDTA) and $3 \mu \mathrm{l}$ of $10 \mathrm{mg} / \mathrm{ml}$ proteinase $\mathrm{K}$ and then incubating for 30 minutes at $37^{\circ} \mathrm{C}$. After extraction with phenol:chloroform, the RNA was precipitated with three volumes of ethanol. The precipitate was recovered by precipitation, washed with $80 \%$ (v/v) ethanol, airdried, and resuspended in $50 \mu \mathrm{l}$ of $\mathrm{H}_{2} \mathrm{O}$. Unincorporated nucleotides were removed by three consecutive rounds of purification using mini Quick Spin Columns for RNA (Roche) according to the manufacturer's instructions and then used for hybridization as described below.

\section{Hybridization of labeled transcript to filter-immobi-} lized probes. Labeled RNA from isolated nuclei was hybridized to immobilized, strand-specific, in-vitro-transcribed RNA probes for firefly luciferase (Photinus pyralis; Pp luc), roo, I-element, HeT-A, mst40, gypsy, rp49, and $a c t 5 C$. RNA probes were transcribed with T7 RNA polymerase from PCR templates prepared with the oligonucleotides reported in Table 1. Pp luciferase was transcribed from the pGL-2 control vector (Promega) using the primers: $5^{\prime}$-gcg taa tac gac tca cta tag GAG AGG AAT TCA TTA TC-3' and 5'-GAA GAG ATA GCC CTG GTT CCT G-3'. Each in-vitro-transcribed RNA probe $(5 \mu \mathrm{g})$ was denatured in $500 \mu \mathrm{l}$ of ice-cold $10 \mathrm{~mm} \mathrm{NaOH}$ and $1 \mathrm{~mm}$ EDTA, transferred to Hybond-XL membrane (Amersham) using a Bio-Dot SF Microfiltration Apparatus (Bio-Rad) according to manufacturer's instructions, and immobilized on the membrane by UV irradiation $(200 \mu$ joules $/ \mathrm{cm}$; Stratalinker, Stratagene). The membrane was prehybridized in Church buffer (Church and Gilbert 1984) for 1 hour at $65^{\circ} \mathrm{C}$ and hybridization was carried out overnight at $65^{\circ} \mathrm{C}$. After hybridization, membranes were washed twice with $2 \times \mathrm{SSC} / 0.1 \%(\mathrm{w} / \mathrm{v}) \mathrm{SDS}$ for 30 minutes at $65^{\circ} \mathrm{C}$ and analyzed by phosphorimagery (Fuji, Tokyo, Japan).

\section{RESULTS \\ Nuclear Run-on Measures Relative Rates of Transcription}

Weiss (1960) demonstrated for the first time that isolated eukaryotic nuclei retain the ability to synthesize RNA. Such RNA synthesis results from transcript elongation by 
Table 1. Primers Used to Generate T7 RNA Polymerase Transcription Templates for Production of Antisense RNA Probes

\begin{tabular}{|c|c|c|}
\hline $\begin{array}{l}\text { Element } \\
\text { or gene }\end{array}$ & Primer se & $\left(5^{\prime}\right.$ to $\left.3^{\prime}\right)$ \\
\hline $\mathrm{roo}$ & 5 primer & taatacgactcactattagggagaccacGGAGGGTTTGATTTAGGGACAGTG \\
\hline & $3^{\prime}$ primer & AGCAGAAGCAGCAACAGCAGTAG \\
\hline HeT-A & $5^{\prime}$ primer & taatacgactcactattagggagaccacGGAGAAGATCGCTGTTCTG \\
\hline & 3' primer & GACACGCGAAAAGCGAAC \\
\hline I-element & 5' primer & taatacgactcactattagggagaccacTTGGCCTTTAGTTTTGATGC \\
\hline & 3' primer & CATCAACACAGCCCAATTGAC \\
\hline $\operatorname{act} 5 \mathrm{C}$ & $5^{\prime}$ primer & gcgtaatacgactcactatagggTGTAGGTGGTCTCGTGGATGC \\
\hline & 3 ' primer & GGCCACCGTGAGAAGATGAC \\
\hline mst40 & $5^{\prime}$ primer & taatacgactcactattagggagaccacAACGATCGCTTGCGATCTAC \\
\hline & 3' primer & TCAAATCAGACGAAGTTCAAGG \\
\hline rp49 & $5^{\prime}$ primer & gcgtaatacgactcactatagggTTACTCGTTCTCTTGAGAACG \\
\hline & 3 ' primer & GACCATCCGCCCAGCATACAG \\
\hline
\end{tabular}

RNA polymerases, rather than initiation of transcription after nuclear isolation (Cox 1976). These experiments led to the establishment of "nuclear run-on" as the standard method for measuring the relative rates of gene transcription (McKnight and Palmiter 1979; Swaneck et al. 1979). In a prototypical nuclear run-on experiment, intact nuclei are isolated by centrifugation and then incubated with exogenous ATP, GTP, CTP, and $\left[\alpha-{ }^{32}\right.$ P]UTP, incorporating radiolabeled nucleotide into transcripts initiated prior to cell lysis but elongated in the isolated nuclei. Radiolabeled nuclear RNA is isolated and then hybridized to strand-specific RNA probes immobilized on a nylon filter. The specificity of hybridization is established by comparing the hybridization signals for the genes of interest to those of control genes whose transcription is presumed to be invariant under the conditions compared (Fig. 1).

We sought to apply the nuclear run-on method to germline tissue from flies. To begin our study, we first tested whether run-on of nuclei isolated from dissected $D$. melanogaster ovaries accurately reflects changes in tran-

Dissect flies and isolate ovaries
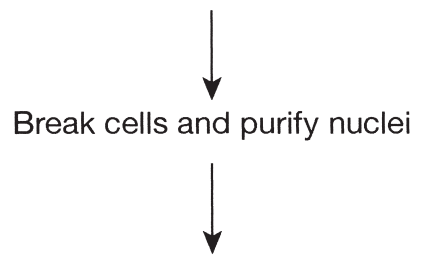

Complete transcription of active genes in presence of ATP, CTP, GTP, \& ${ }^{32} \mathrm{P} \alpha$-UTP

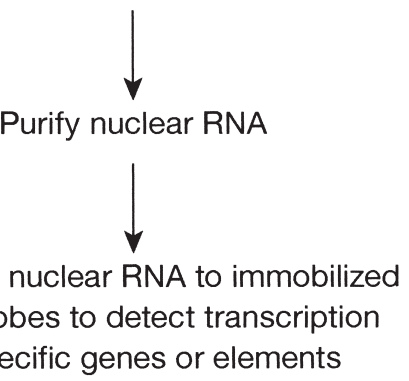

Figure 1. Schematic of nuclear run-on analysis. scriptional rates. We compared the apparent transcriptional rates of the $R p L 32$ gene (commonly known as $r p 49$ ) in nuclei isolated from ovaries of wild-type flies containing two copies of $r p 49(2 \times r p 49)$ to that in mutant Df(3R)L127/TM6; Dp(3;1)B152/Dp(3;1)B152 flies in which one copy of the $r p 49$ locus on the third chromosome is deleted and each $\mathrm{X}$ chromosome contains an additional copy of the locus, for a total of three copies of $r p 49$ (hereafter, $3 \times$ rp 49). As a control, we used the act5C gene. Hybridization to the firefly luciferase ( $P p$ Luc) antisense transcript, whose sequence shares little similarity with any gene in D. melanogaster, provided a measure of the nonspecific background. The steady-state mRNA level in the ovaries of the $3 \times r p 49$ flies was greater by a factor of 1.84 \pm 0.39 (average \pm standard deviation) than in the ovaries of the $2 \times r p 49$ flies (Fig. 2A). Transcription of $r p 49$ in the ovaries with three copies of the gene was greater by a factor of $1.75 \pm 0.24$ (average \pm standard deviation for three independent trials) than in the ovaries from flies bearing two copies of the rp49 gene (Fig. 2B). We conclude that

A

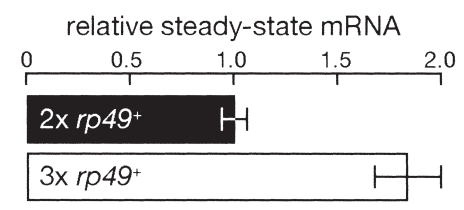

B

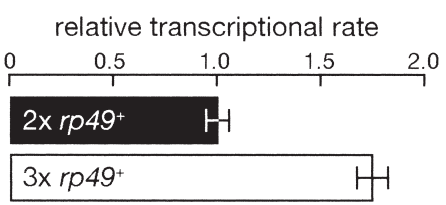

Figure 2. Nuclear run-on analysis can detect small changes in transcriptional rates. $(A)$ Relative steady-state mRNA concentration in ovaries from flies with two or three copies of the rp49 gene. $(B)$ Nuclear run-on assay in ovaries from flies with two or three copies of the rp 49 gene. The assay readily detected the approximately 1.5 -fold change in the transcription of $r p 49$ between the wild-type rp49/rp49 (2x rp49) and the Df(3R)L127/TM6; Dp(3;1)B152/Dp(3;1)B152 (3× rp49) flies. 


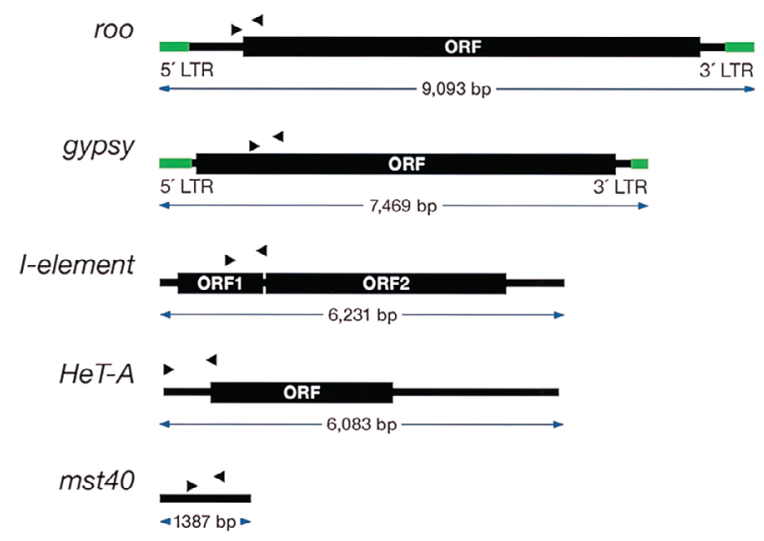

Figure 3. Position of primers used to prepare T7 RNA polymerase PCR templates to synthesize the antisense RNA probes used to detect repetitive elements.

the nuclear run-on assay readily detected an approximately 1.5 -fold change in the transcriptional rate of a housekeeping gene in D. melanogaster ovaries.

A central assumption in this assay is that only transcripts initiated by RNA pol II prior to cell lysis are extended during the radiolabeling reaction. If this assumption is justified, the amount of $\left[\alpha_{-}^{32}\right.$ P]UTP incorporated in an elongating transcript should decline with time, as individual molecules of RNA pol II complete transcription but do not initiate new rounds of RNA synthesis in vitro.

Labeled transcripts were isolated and hybridized to strand-specific RNA probes for four different repetitive sequences: two long terminal repeat (LTR) retrotransposons (roo and gypsy) and two non-LTR retrotransposons (I-element and HeT-A). Probes for two single-copy genes, $a c t 5 C$ and $r p 49$, served as controls. The positions of the primers used to make polymerase chain reaction (PCR) templates for RNA probe transcription by T7 RNA polymerase are diagrammed in Figure 3. If no reinitiation occurs during the run-on reaction, transcription rates should saturate when there are no more unfinished transcripts left to label. We find that after about 40 minutes, transcriptional rates saturated, consistent with RNA pol II having elongated all available transcripts without reinitiating new rounds of transcription (Fig. 4).

\section{Measuring the Rates of Repetitive Element Transcription}

Hybridization-based nuclear run-on was conceived to measure the relative transcriptional rates of single-copy genes (McKnight and Palmiter 1979). Because repetitive elements are multicopy, we were concerned that their high aggregate rates of RNA synthesis might saturate the immobilized RNA probes, preventing our detecting changes in transcriptional rates. To exclude this possibility, we performed nuclear run-on using armi homozygous mutant ovaries, in which transposon silencing is derepressed; $100 \%, 50 \%, 25 \%$, and $10 \%$ of the ${ }^{32} \mathrm{P}$-radiolabeled RNA was hybridized to $5 \mu \mathrm{g}$ of immobilized RNA probes for the transposons roo, gypsy, I-element, and $H e T-A$, the repetitive sequence $m s t 40$, and the single-copy
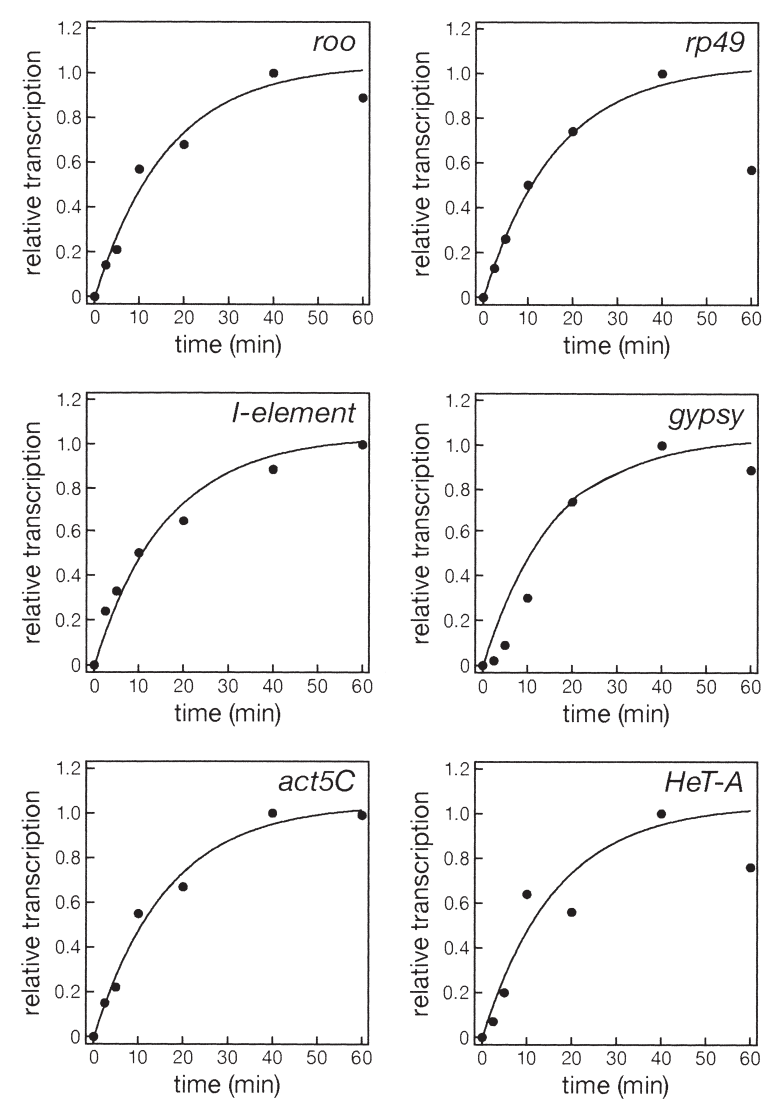

Figure 4. Nuclear run-on likely measures the rate of transcription without substantial reinitiation by RNA pol II, because transcriptional rates saturate with time.

gene $a c t 5 C$. For all six genes, the rate of transcription decreases linearly with dilution, even for $H e T-A$ retrotransposon, whose steady-state transcript levels rise approximately 170-fold in the absence of Armi (Fig. 5) (Vagin et al. 2006). We conclude that our experimental conditions can accurately measure repetitive element transcriptional rates despite their high copy number.

\section{Repetitive Elements Are Transcribed by RNA pol II}

To establish that our assay detects RNA synthesis, we conducted the run-on in the presence of three RNA chain terminators: 3'-deoxy ATP, 3'-deoxy CTP, and 3'-deoxy GTP. Consistent with RNA synthesis, run-on transcription decreased dramatically in the presence of the RNA chain terminators for all six genes examined, act5C, rp 49, gypsy, roo, I-element, and HeT-A (Fig. 6).

In D. melanogaster, $10 \mu \mathrm{g} / \mathrm{ml} \alpha$-amanitin inhibits transcription by RNA pol II, but not by RNA pol I or III. To test whether RNA pol II predominantly transcribes repetitive elements in D. melanogaster, the nuclear run-on assay was conducted on nuclei preincubated with $10 \mu \mathrm{g} / \mathrm{ml}$ $\alpha$-amanitin for 10 minutes on ice. Hybridization signals were compared with those from mock-preincubated nuclei. $\alpha$-Amanitin reduced repetitive element transcription by an amount comparable to the reduction observed 

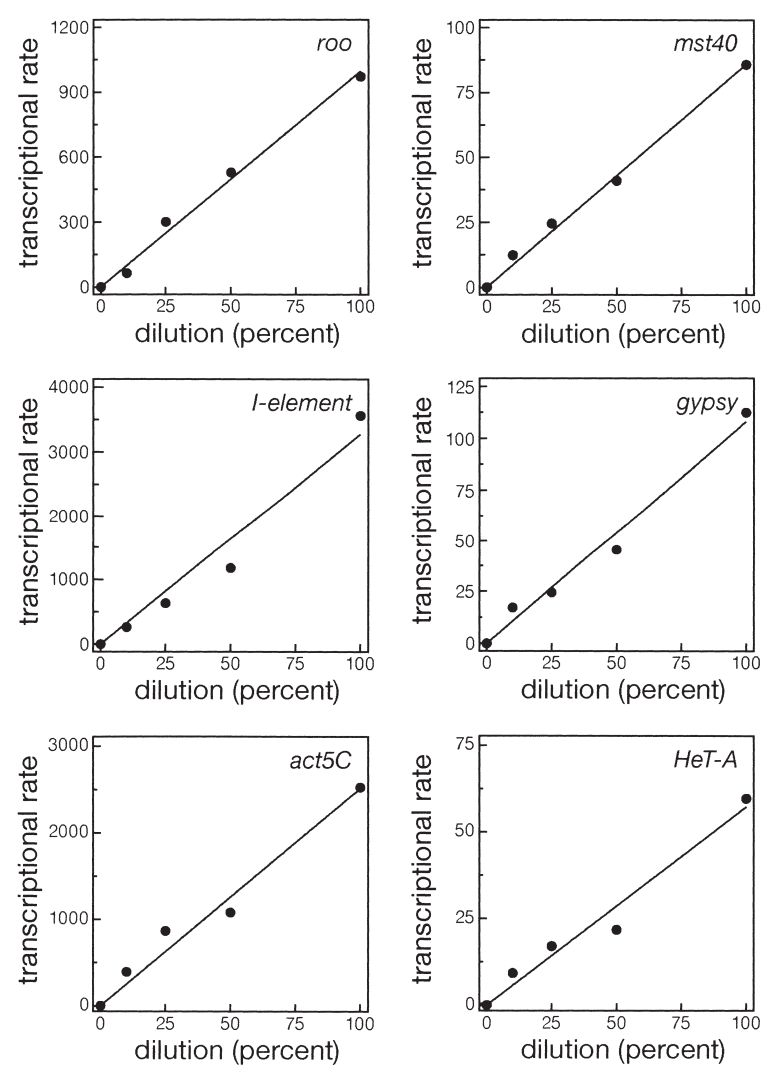

Figure 5. Nuclear run-on can detect the rates of repetitive element transcription. Dilution analysis detects no saturation of signal when registering repetitive element transcription in a nuclear run-on assay.

for the single-copy control genes act $5 \mathrm{C}$ and $r p 49$ (Fig. 6). We conclude that in flies, repetitive elements, like proteincoding genes, are transcribed by RNA pol II.

\section{Repetitive Elements in D. melanogaster Ovaries Are Silenced Posttranscriptionally}

In armi homozygous mutants, the steady-state RNA concentration increases by a factor of three for the LTR- retrotransposon gypsy and more than 8-fold for $m s t 40$ (Vagin et al. 2006). mst40 sequences are located in region 40 , at the base of chromosome $2 L$, close to or within the $\beta$-heterochromatin (Russell and Kaiser 1994). gypsy element insertions cause frequent mutations in $D$. melanogaster (Peifer and Bender 1988). Interestingly, studies of reversion of gypsy-induced mutations demonstrated that it is not simply the insertion of gypsy DNA that causes the mutant phenotype, because most gypsyinduced phenotypes can be suppressed by mutations in suppressor of Hairy wing $[\mathrm{su}(\mathrm{Hw})]$ (Peifer and Bender 1988). The 5'UTR (untranslated region) of gypsy contains an insulator sequence that binds $\mathrm{Su}(\mathrm{Hw})$ protein and is the only part of gypsy required to block the interaction of enhancers with the promoters they regulate. Insertion of this insulator sequence between an enhancer and a promoter by insertion of a gypsy element uncouples the enhancer from the promoter (Gause et al. 2001).

The gypsy element can only be mobilized in male and female progeny of mothers that both contain active copies of gypsy and are homozygous for permissive flamenco (flam) alleles (Chalvet et al. 1998; Sarot et al. 2004). What protein-coding genes, if any, reside in flam is unknown.

To determine the mechanism by which Armi silences mst 40 and gypsy, we analyzed ovaries from heterozygous and homozygous armi mutant females by nuclear run-on (Fig. 7). We found no significant change in transcription between armi/+ and armi/armi ovaries for either mst 40 or gypsy. We conclude that in the female germ line of $D$. melanogaster, Armi acts to silence these two repetitive elements posttranscriptionally, rather than transcriptionally.

\section{CONCLUSIONS}

We have shown that nuclear run-on can be used to measure changes in transcriptional rates in the female $D$. melanogaster germ line. Our data indicate that as little as an approximately 1.5 -fold change in the rate of transcription can be detected by this method. Our nuclear run-on protocol likely measures changes in transcriptional elongation, because rates of transcription decline with time, consistent with a low rate of pol II reinitiation in the isolated nuclei. Our data support the view that the nuclear run-on technique can be applied not only to single-copy genes, but

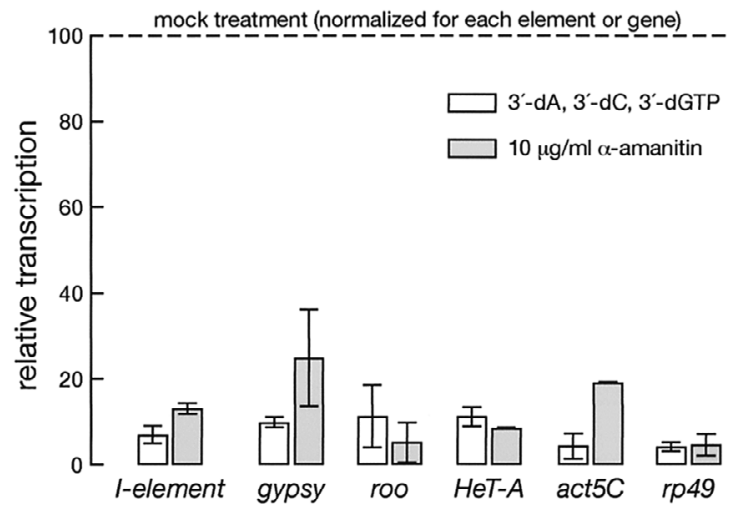

Figure 6. Repetitive element transcripts are largely RNA pol II products.
A
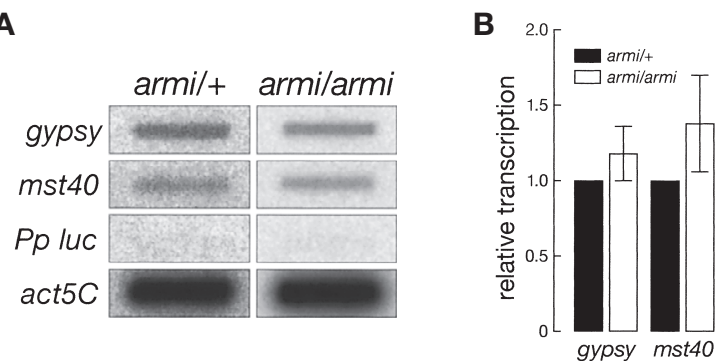

Figure 7. (A) A nuclear run-on experiment representative of the data used for the quantitative analysis in $B .(B)$ The transcriptional rates of the retrotransposon gypsy and the repetitive sequence $m s t 40$ do not change significantly when silencing is lost in homozygous mutant armi ovaries. The average ( \pm standard deviation) relative to the transcriptional rate of $a c t 5 C$ is presented. 
also to multicopy transcriptional units such as repetitive elements and transposons. Surprisingly, we find that the retrotransposon gypsy and the repetitive sequence mst40 are silenced posttranscriptionally in fly ovaries. Whether repetitive elements in general are silenced posttranscriptionally in the fly germ line remains to be established.

\section{ACKNOWLEDGMENTS}

We thank members of the Zamore lab for helpful discussions and comments on the manuscript and Alicia Boucher for assistance with fly husbandry. P.D.Z. is a W.M. Keck Foundation Young Scholar in Medical Research. This work was supported in part by grants from the National Institutes of Health to P.D.Z. (GM62862 and GM65236).

\section{REFERENCES}

Allshire R.C., Nimmo E.R., Ekwall K., Javerzat J.P., and Cranston G. 1995. Mutations derepressing silent centromeric domains in fission yeast disrupt chromosome segregation. Genes Dev. 9: 218.

Bernard P., Maure J.F., Partridge J.F., Genier S., Javerzat J.P., and Allshire R.C. 2001. Requirement of heterochromatin for cohesion at centromeres. Science 294: 2539.

Buhler M., Verdel A., and Moazed D. 2006. Tethering RITS to a nascent transcript initiates RNAi- and heterochromatindependent gene silencing. Cell 125: 873 .

Chalvet F., di Franco C., Terrinoni A., Pelisson A., Junakovic N., and Bucheton A. 1998. Potentially active copies of the gypsy retroelement are confined to the $\mathrm{Y}$ chromosome of some strains of Drosophila melanogaster possibly as the result of the female-specific effect of the flamenco gene. $J$. Mol. Evol. 46: 437.

Church G.M. and Gilbert W. 1984. Genomic sequencing. Proc. Natl. Acad. Sci. 81: 1991.

Copenhaver G.P., Nickel K., Kuromori T., Benito M.I., Kaul S., Lin X., Bevan M., Murphy G., Harris B., Parnell L.D., et al. 1999. Genetic definition and sequence analysis of Arabidopsis centromeres. Science 286: 2468.

Cox R.F. 1976. Quantitation of elongating form A and B RNA polymerases in chick oviduct nuclei and effects of estradiol. Cell 7: 455.

Djupedal I., Portoso M., Spahr H., Bonilla C., Gustafsson C.M., Allshire R.C., and Ekwall K. 2005. RNA Pol II subunit Rpb7 promotes centromeric transcription and RNAi-directed chromatin silencing. Genes Dev. 19: 2301.

Elgin S.C. and Grewal S.I. 2003. Heterochromatin: Silence is golden. Curr. Biol. 13: R895.

Forrester W.C., Novak U., Gelinas R., and Groudine M. 1989. Molecular analysis of the human beta-globin locus activation region. Proc. Natl. Acad. Sci. 86: 5439.

Gause M., Morcillo P., and Dorsett D. 2001. Insulation of enhancer-promoter communication by a gypsy transposon insert in the Drosophila cut gene: Cooperation between suppressor of hairy-wing and modifier of mdg4 proteins. Mol. Cell. Biol. 21: 4807.

Gilbert D.M. 2002. Replication timing and transcriptional control: Beyond cause and effect. Curr. Opin. Cell Biol. 14: 377.

Grummt I. and Pikaard C.S. 2003. Epigenetic silencing of RNA polymerase I transcription. Nat. Rev. Mol. Cell Biol. 4: 641.

Heard E. 2005. Delving into the diversity of facultative heterochromatin: The epigenetics of the inactive $\mathrm{X}$ chromosome. Curr. Opin. Genet. Dev. 15: 482.

Henikoff S. 1992. Position effect and related phenomena. Curr. Opin. Genet. Dev. 2: 907.

Holmquist G.P., Kapitonov V.V., and Jurka J. 1998. Mobile genetic elements, chiasmata, and the unique organization of beta-heterochromatin. Cytogenet. Cell Genet. 80: 113.

Huang J. and Moazed D. 2006. Sister chromatid cohesion in silent chromatin: Each sister to her own ring. Genes Dev. 20: 132.

Huisinga K.L., Brower-Toland B., and Elgin S.C. 2006. The contradictory definitions of heterochromatin: Transcription and silencing. Chromosoma 115: 110.

Kalmykova A.I., Klenov M.S., and Gvozdev V.A. 2005. Argonaute protein PIWI controls mobilization of retrotransposons in the Drosophila male germline. Nucleic Acids Res. 33: 2052.

Kato H., Goto D.B., Martienssen R.A., Urano T., Furukawa K., and Murakami Y. 2005. RNA polymerase II is required for RNAi-dependent heterochromatin assembly. Science 309: 467.

Kazazian H.H.J. 2004. Mobile elements: Drivers of genome evolution. Science 303: 1626 .

Kim A. and Dean A. 2004. Developmental stage differences in chromatin subdomains of the beta-globin locus. Proc. Natl. Acad. Sci. 101: 7028.

Lawrence R.J. and Pikaard C.S. 2004. Chromatin turn ons and turn offs of ribosomal RNA genes. Cell Cycle 3: 880 .

Lawrence R.J., Earley K., Pontes O., Silva M., Chen Z.J., Neves N., Viegas W., and Pikaard C.S. 2004. A concerted DNA methylation/histone methylation switch regulates rRNA gene dosage control and nucleolar dominance. Mol. Cell 13: 599.

Lewis M.S. and Pikaard C.S. 2001. Restricted chromosomal silencing in nucleolar dominance. Proc. Natl. Acad. Sci. 98: 14536.

Mahtani M.M. and Willard H.F. 1998. Physical and genetic mapping of the human $\mathrm{X}$ chromosome centromere: Repression of recombination. Genome Res. 8: 100.

Martienssen R.A. and Colot V. 2001. DNA methylation and epigenetic inheritance in plants and filamentous fungi. Science 293: 1070 .

McKnight G.S. and Palmiter R.D. 1979. Transcriptional regulation of the ovalbumin and conalbumin genes by steroid hormones in chick oviduct. J. Biol. Chem. 254: 9050.

Nimmo E.R., Pidoux A.L., Perry P.E., and Allshire R.C. 1998. Defective meiosis in telomere-silencing mutants of Schizosaccharomyces pombe. Nature 392: 825.

Nolan T., Braccini L., Azzalin G., De Toni A., Macino G., and Cogoni C. 2005. The post-transcriptional gene silencing machinery functions independently of DNA methylation to repress a LINE1-like retrotransposon in Neurospora crassa. Nucleic Acids Res. 33: 1564.

Pal-Bhadra M., Leibovitch B.A., Gandhi S.G., Rao M., Bhadra U., Birchler J.A., and Elgin S.C. 2004. Heterochromatic silencing and HP1 localization in Drosophila are dependent on the RNAi machinery. Science 303: 669.

Peifer M. and Bender W. 1988. Sequences of the gypsy transposon of Drosophila necessary for its effects on adjacent genes. Proc. Natl. Acad. Sci. 85: 9650.

Pidoux A.L. and Allshire R.C. 2005. The role of heterochromatin in centromere function. Philos. Trans. R. Soc. Lond. B Biol. Sci. 360: 569.

Puechberty J., Laurent A.M., Gimenez S., Billault A., BrunLaurent M.E., Calenda A., Marcais B., Prades C., Ioannou P., Yurov Y., and Roizes G. 1999. Genetic and physical analyses of the centromeric and pericentromeric regions of human chromosome 5: Recombination across 5cen. Genomics 56: 274.

Riddle N.C. and Elgin S.C. 2006. The dot chromosome of Drosophila: Insights into chromatin states and their change over evolutionary time. Chromosome Res. 14: 405.

Russell S.R. and Kaiser K. 1994. A Drosophila melanogaster chromosome 2L repeat is expressed in the male germ line. Chromosoma 103: 63.

Sarot E., Payen-Groschene G., Bucheton A., and Pelisson A. 2004. Evidence for a piwi-dependent RNA silencing of the gypsy endogenous retrovirus by the Drosophila melanogaster flamenco gene. Genetics 166: 1313.

Savitsky M., Kwon D., Georgiev P., Kalmykova A., and 
Gvozdev V. 2006. Telomere elongation is under the control of the RNAi-based mechanism in the Drosophila germline. Genes Dev. 20: 345.

Schubeler D., Scalzo D., Kooperberg C., van Steensel B., Delrow J., and Groudine M. 2002. Genome-wide DNA replication profile for Drosophila melanogaster: A link between transcription and replication timing. Nat. Genet. 32: 438.

Sijen T. and Plasterk R.H. 2003. Transposon silencing in the Caenorhabditis elegans germ line by natural RNAi. Nature 426: 310 .

Slawson E.E., Shaffer C.D., Malone C.D., Leung W., Kellmann E., Shevchek R.B., Craig C.A., Bloom S.M., Bogenpohl J.N., Dee J., et al. 2006. Comparison of dot chromosome sequences from $D$. melanogaster and $D$. virilis reveals an enrichment of DNA transposon sequences in heterochromatic domains. Genome Biol. 7: R15.

So W.V. and Rosbash M. 1997. Post-transcriptional regulation contributes to Drosophila clock gene mRNA cycling. EMBO J. 16: 7146.
Swaneck G.E., Nordstrom J.L., Kreuzaler F., Tsai M.J., and O'Malley B.W. 1979. Effect of estrogen on gene expression in chicken oviduct: Evidence for transcriptional control of ovalbumin gene. Proc. Natl. Acad. Sci. 76: 1049.

Vagin V.V., Sigova A., Li C., Seitz H., Gvozdev V., and Zamore P.D. 2006. A distinct small RNA pathway silences selfish genetic elements in the germline. Science 313: 320.

Volpe T.A., Kidner C., Hall I.M., Teng G., Grewal S.I., and Martienssen R.A. 2002. Regulation of heterochromatic silencing and histone H3 lysine-9 methylation by RNAi. Science 297: 1833.

Weintraub H., Larsen A., and Groudine M. 1981. Alpha-Globingene switching during the development of chicken embryos: Expression and chromosome structure. Cell 24: 333.

Weiss S.B. 1960. Enzymatic incorporation of ribonucleoside triphosphates into the interpolynucleotide linkages of ribonucleic acid. Proc. Natl. Acad. Sci. 46: 1020.

Zacharias H. 1995. Emil Heitz (1892-1965): Chloroplasts, heterochromatin, and polytene chromosomes. Genetics 141: 7. 


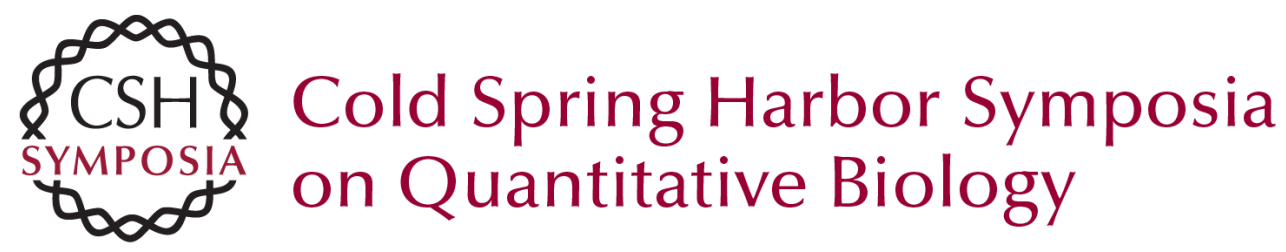

\title{
Measuring the Rates of Transcriptional Elongation in the Female Drosophila melanogaster Germ Line by Nuclear Run-on
}

\author{
A. SIGOVA, V. VAGIN and P.D. ZAMORE
}

Cold Spring Harb Symp Quant Biol 2006 71: 335-341

Access the most recent version at doi:10.1101/sqb.2006.71.031

$\begin{array}{ll}\text { References } & \text { This article cites } 48 \text { articles, } 25 \text { of which can be accessed free at: } \\ \text { http://symposium.cshlp.org/content/71/335.full.html\#ref-list-1 }\end{array}$

\section{License}

Email Alerting Receive free email alerts when new articles cite this article - sign up in Service the box at the top right corner of the article or click here. 